\title{
As sociedades indígenas, a história e a escola
}

\author{
The indigenous society, history and teaching
}

Maria Cristina Bohn Martins*

RESUMO no Brasil, entre a pesquisa e o ensino de temas the academic research in Brazil consist on the relativos às sociedades indígenas. Para isto re- object studied of this paper. Therefore, ponder flete sobre ourocentrismo presente nasconcep- about the eurocentrism present on the ções da historiografia tradicional, e sobre as crí- traditional historiography. Finally, discuss ticas que lhes são feitas atualmente. Por fim, around the modern schedule of this theme in avalia a repercussão da moderna agenda de pes- the scholarship practices.

quisa sobre este tema nas práticas escolares.

PALAVRAS-CHAVE: Nova História Indígena; Pesquisa; Ensino; Escola; Brasil.
KEYWORDS: New Indigenous

History;

Ronda os relatos indígenas uma tensão constante entre a fragmentação de histórias múltiplas (...) e a reafirmação cardeal do processo fundamental de transformação, que constitui o embasamento ontológico da cultura. Já não é possível sonhar com uma existência indígena independente das pressões da ocupação do território (...) e as exigências políticas impõem às sociedades indígenas do Brasil uma etnização que elas não escolheram(,). Em outras palavras, definir em face da sociedade que a engloba uma identificação específica. (...) O drama (...)é, talvez, que para sua sobrevivência elas recorreram sistematicamente a uma alteridade, de vários tipos na verdade, cujos vestígios durante muito tempo tentaram com determinação apagar Patrick Menget (1999)

A afirmação de que a imagem das populações autóctones do território que hoje definimos como brasileiro foi construída -tanto pela historiografia mais

\footnotetext{
* Doutora em História pela Pontifícia Universidade Católica do Rio Grande do Sul (PUC-RS) e Professora Titular da Universidade do Vale do Rio dos Sinos (UNISINOS) / Brasil.
} 
tradicional, quanto pelos livros didáticos ${ }^{1}$ que a reproduzem-, de modo simplificador e estereotipado já não se constitui mais em matéria de discussão. Pode-se também dizer, por outro lado, que os historiadores investem hoje um grande esforço em revisar estas considerações, na constituição do que se tem chamado de uma "nova história indígena".

Começo, portanto, esta reflexão lembrando que, desde as últimas décadas do século passado, nosso campo de conhecimento renovou-se profundamente. Além de repensar seus objetos e métodos, os profissionais a ele ligados têm refletido sobre o próprio estatuto da história, seu lugar em meio às ciências sociais e sua capacidade explicativa.

No Brasil, é possível observar que cresceu consideravelmente, nas últimas décadas, a atenção dos historiadores a este tema (o das populações indígenas, sua história antes e depois da expansão européia sobre o Novo Mundo), mesmo que timidamente se compararmos a nossa situação àquela de outros países (como o México e o Peru, por exemplo). Como afirmou Manoela Carneiro da Cunha, em obra que se constitui em um dos primeiros exemplos desta nova preocupação, "sabe-se pouco da história indígena: nem a origem, nem as cifras de população são seguras, muito menos o que realmente aconteceu. Mas progrediu-se, no entanto: hoje está mais claro, pelo menos a extensão do que não se sabe" (CUNHA, 1992: 11).

Ainda que devamos reconhecer as enormes lacunas existentes no conhecimento que possuímos sobre os povos nativos das Américas, podemos dizer que a sua história afirma-se hoje como um campo de estudos em forte expansão, atraindo interesse de investigadores em várias instituições de ensino e pesquisa no país. Os subsídios provenientes da história e da antropologia, contribuem atualmente com ele, tanto no âmbito da pesquisa empírica, quanto no refinamento do equipamento conceitual pertinente ao tema. Tais aportes ajudam a romper com noções essencializadas das culturas indígenas, questionando antigos dualismos como aqueles que contrapõem "índios puros e aculturados", "resistência e aculturação" e "processo histórico e estruturas culturais", os quais acabavam por selar a "crônica da destruição" dos povos indígenas.

\footnotetext{
1 Os termos "livros didáticos", "livros escolares", "textos" e "materiais escolares", não estão sendo aqui problematizados, mas usados indistintamente e considerados como livros escritos e produzidos especificamente para seu uso no ensino.
} 


\section{"Vanishing people"?}

Uma das noções mais freqüentes acerca do resultado da conquistacolonização do Novo Mundo é aquela que apresenta, como efeito deste processo, o "desaparecimento" das sociedades nativas. As espantosas cifras da queda na demografia indígena que se seguiu à chegada dos europeus, bem como os relatos dos cronistas coloniais ${ }^{2}$ sobre os efeitos devastadores da violência, 3 das doenças, da má nutrição, do excesso de trabalho e mesmo do stress sobre os nativos foram, sem dúvida, muito importantes para a construção desta narrativa.

Importa ainda ressaltar que esta perspectiva ganhou grande evidência na produção associada à chamada "Visão dos Vencidos"4 que, ao fazer a denúncia do colonialismo europeu, destacando as brutalidades a que foram submetidas as populações autóctones, distinguiu fortemente este ângulo da questão. Ao "trauma da conquista" evidenciado, por exemplo, na elegia escrita para prantear a morte de Atahualpa, 5 teriam se seguido o caos e a desolação. As obras que se filiam a esta corrente falam em testemunhos dos "sobreviventes", abatidos por um "profundo trauma", bem como nos trágicos efeitos da "destruição da cultura indígena”, perspectivas que tiveram forte aceitação no âmbito escolar. Entretanto, como adverte John Monteiro (2001), embora simpática aos índios, esta visão do passado perpetua -inadvertidamente- uma compreensão que acaba por se mostrar muito pouco favorável a eles.

De acordo com Mathew Restall, as sociedades indígenas aparecem nesta narrativa, como se fizessem parte de uma espécie de Arcádia, incapazes -em sua inocência- de sobreviver à experiência da invasão européia. Se esta dimensão romantiza as sociedades nativas, uma outra aposta na sua "inferioridade", a qual

2 É famosa, por exemplo, a avaliação feita nos inícios do século XVII por Felipe Guaman Poma de Ayala, que afirmou em sua Nueva Crónica y Buen Gobierno (1615): "Não há remédio, e os índios estão se acabando".

3 O dominicano Bartolomeu de las Casas é, sem dúvida, o nome mais conhecido desta corrente de pensamento crítico acerca do impacto da conquista européia sobre os povos do Novo Mundo.

4 Nomes e obras representativas desta corrente historiográfica são: Nathan Watchel (1976) e Miguel León-Portilla (1984 e 1985).

5 "Acabou-se já em tuas mãos o sangue: apagou-se em teus olhos a luz; no fundo da mais brilhante estrela caiu teu olhar (...). Sob estranho império acumulados os martírios e destruídos; perplexos, extraviados, negada a memória; sozinhos; morta a sombra que protege, choramos; sem ter a quem ou aonde nos voltar, estamos delirando" (LEON-PORTILLA, 1985: 137). 
as impediria de resistir à ocidentalização imposta. Assim, "ao longo dos séculos os europeus imaginaram e inventaram a derrocada cultural e social das sociedades nativas americanas" (2006: 184), ${ }^{6}$ cujo corolário foi o seu desaparecimento.

É justamente esta noção, a de que as sociedades indígenas seriam "evanescentes", isto é destinadas a desaparecer (vanishing people), que tem sido criticada na atualidade. Antes disto, porém, ela influenciou fortemente a política dos Estados (tanto coloniais, quanto independentes) com suas comunidades indígenas, quase sempre pautada na noção da "transitoriedade" da condição indígena e na proposição de políticas assimilatórias. Assim, a legislação acerca dos índios tratou de buscar a sua "civilização" e inserção na comunidade (cristã e, depois, nacional7), num trabalho para o qual foram mobilizados os agentes da Igreja e, a seu tempo, dos Estados republicanos.

Também a historiografia, nas Américas e no Brasil, comungou desta idéia, assim como pensadores das mais diversas épocas. Efetivamente, observando as avaliações postuladas por autores tão diversos, uns dos outros, como Carl Von Martius ou Varnhagen, nos Oitocentos, e Florestan Fernandes e Darcy Ribeiro, no século passado, por exemplo, percebemos que elas se aproximam quanto ao profundo pessimismo com o qual eles ponderavam sobre o futuro dos povos indígenas.

Sobretudo, a partir do século XIX predominou a tese, baseada no paradigma evolucionista, segundo a qual as populações indígenas estavam condenadas ao desaparecimento: ou pela extinção física, ou pela "aculturação". É sabido que o famoso naturalista Alexander Von Humboldt, por exemplo, expressou no México sua impressão de que o "melhor tipo de índios", entre os quais se poderia supor a existência de um "certo grau de cultura intelectual", havia perecido em grande parte já no começo da conquista espanhola (HALPERIN DONGUI: 1997). Já no Brasil, a história esposava a mesma tese, tal como a expressaram Varnhagen, na década de 1850 (para os índios, "não há história, apenas etnografia”), ou Von Martius (que se pronunciou sobre o "já

6 Segundo o autor, as sociedades nativas não eram nem bárbaras nem idílicas, e sim tão civilizadas e imperfeitas quanto as européias, sendo suas respostas à invasão européias variadas e baseadas em avaliações de seus próprios interesses (RESTALL, 2006: 184)

7 O "Estatuto do Índio" (Lei n. 6001 de 1973) elaborado ao tempo dos governos militares e ainda em vigor no país, afirma o propósito de integrar os indígenas "progressiva e harmoniosamente" à comunhão nacional. 
visível gérmen do desaparecimento rápido" destes povos) (MONTEIRO, 2006: 170).

Os pensadores do Império, ao se enfrentarem com o tema da "gênese da nação brasileira", instituíram os índios tupis como um dos pilares da nacionalidade, mas sempre em referência a um índio do passado, um índio já extinto. Paradoxalmente, na mesma época em que se cunhava o poderoso "mito das três raças" formadoras do povo brasileiro, as populações indígenas (em especial os botocudos) com as quais interagia a sociedade brasileira, eram tidas como "bárbaras", integrantes das "hordas selvagens", que as luzes da moderna civilização deveria fazer desaparecer (MONTEIRO, 2001).

Depois, nas décadas centrais do século XX, antropólogos e historiadores entenderam que, diante do movimento das frentes de expansão da moderna sociedade nacional, as populações indígenas seriam levadas a uma inexorável perda da sua peculiaridade cultural, ou acabariam por reprisar a história da destruição que havia exterminado inúmeros povos no passado. Os últimos anos assistiram, contudo, no Brasil e nas Américas em geral, uma forte reversão desta expectativa, apresentando, como componente importante, um novo protagonismo reivindicado pelos próprios indígenas.

\section{Línguas vivas, de povos vivos}

Em junho de 2002, uma mensagem eletrônica circulou através da lista de Discussões da Associação Nacional de Pesquisadores em História da América Latina e do Caribe (ANPHLAC) ${ }^{8}$ indagando o mundo acadêmico acerca da pertinência (ou não) da utilização do termo "índio". A referida mensagem repercutia o debate travado originalmente no âmbito da "H-LATAM"9 envolvendo historiadores das mais prestigiosas instituições européias e norteamericanas.

Entre as diversas manifestações que ali se expressaram, a grande maioria defendeu a idéia da inadequação do uso de um conceito incorreto (porque cria uma unidade inexistente) e cujas implicações são claramente colonialistas. Em menor número estiveram os historiadores que categorizaram a discussão como

8 Conservando a sigla, denomina-se atualmente Associação Nacional de Pesquisadores em História das Américas.

9 A lista de discussão tem o endereço eletrônico: h-latam@h-net.msu.edu. 
inócua, atenta em acolher os ditames do "politicamente correto", e como uma preocupação mais relacionada à maneira pela qual os norte-americanos vivenciam seus compromissos políticos. Desta forma, a maior parte daqueles que se manifestou, enfatizou a necessidade de utilizarmos uma linguagem respeitosa com os personagens com os quais manejamos em nosso ofício, assinalou-se, ainda, a necessidade de prestarmos atenção aos termos pelos quais os próprios indígenas preferiam ser chamados.

Mais recentemente, no início do ano de 2009, circulou na Web uma matéria originada do jornal La Nación de Santiago do Chile de 14 de janeiro. Nela, dava-se a conhecer o desejo e a ação das comunidades quéchuas existentes no país, no sentido de dar vida a uma "Academia" de sua própria língua, tal como já feito pelos aymaras e rapa nuis. De acordo com o referido texto, uma pesquisa conduzida por um grupo de investigadores formado por mais de 30 lingüistas, entre chilenos, franceses, norte-americanos e outros, levantou a existência de 552 povos indígenas falantes de 420 línguas ameríndias (provenientes de 99 famílias lingüísticas) no continente, numa diversidade que não encontra paralelo em nenhuma parte do mundo. ${ }^{10}$

De outra parte, no Brasil, depois de ter estado em contínuo declínio desde o século XVI, a demografia indígena atualmente vive outra realidade, que é de estabilidade e, talvez, até de um certo crescimento. Segundo as informações do Instituto Socioambiental, ${ }^{11}$ a maioria dos povos indígenas tem crescido em torno de $3,5 \%$ ao ano ${ }^{12}$, muito mais do que a média de $1,6 \%$ estimada no período de

10 De acordo com o Informe da XV Cumbre Iberoamericana (2005) na América Latina uma série de línguas indígenas são faladas por um número em torno de 18 milhões de pessoas. No México seriam cerca de 50 delas, enquanto na Guatemala haveria 21 dialetos pertencentes ao tronco maia. Outros países multilingües apontados são a Colômbia e o Peru, onde são utilizados aproximadamente 70 e 66 idiomas, respectivamente. Na Bolívia, destaca-se o aymara, embora se falem, além desta, mais 35 línguas. De todos os idiomas ameríndios, aquele que possui um maior número de falantes é o quechua, utilizado por sete milhões de pessoas apenas no Peru, Equador, Bolívia e Colômbia, seguindo-se o guarani, com três milhões no Paraguai, Brasil, Bolívia e Argentina. Outras línguas importantes são o aymara, com um milhão e meio de falantes no Peru e na Bolívia, o náhuatl, com um milhão de falantes no México, e o quiche, com quase um milhão de habitantes comunicando-se nesta língua na Guatemala. Ver: <http://www.cumbre-iberoamericana.org >. Acesso em março de 2006.

11 Ver: <www.socioambiental.org.br>.

12 Como veremos, ao lado do crescimento vegetativo, há que se lembrar, relativamente ao aumento da população indígena, do fenômeno da "autodeclaração". Este, que implica na atitude de assumir identidades étnicas antes negadas, está ligado, entre outros fatores, aos direitos que passam a ser assegurados constitucionalmente aos índios. 
1996 a 2000 para a população brasileira em geral. ${ }^{13}$ Nos últimos anos, tivemos como avanço na questão indígena também uma realidade de protagonismo dos próprios índios. Povos que eram tidos como fadados à extinção hoje estão vivos, atuantes, presentes, organizados e cobrando do Poder Público a implementação de seus direitos.

Tais dados são, contudo, apenas um dos elementos que evidenciam a inconsistência da tese do "aniquilamento", ou mesmo do "desaparecimento" das populações indígenas americanas. A realidade mostrou o equívoco das políticas que, pensando-os como seres transitórios, tentou dissolvê-los na "comunhão nacional". Efetivamente, os últimos anos conheceram o fenômeno dos chamados "índios emergentes", isto é, de populações que passam a reivindicar pública e oficialmente a condição de indígenas.

\section{O novo ativismo indígena e a reivindicação étnica}

A reivindicação para si de uma especial condição étnica parte, muitas vezes, de grupos que, miscigenados e territorialmente esbulhados ao longo do tempo, reencontram, no presente, contextos políticos e históricos favoráveis à retomada de identidades coletivas indígenas. Assim como no Brasil, situações semelhantes são conhecidas em outros Estados nacionais contemporâneos como, por exemplo, a Bolívia ou o Chile. Casos desta natureza, que os especialistas vêm qualificando de etnogêneses, ${ }^{14}$ são identificados desde a década de 70, mas se tornaram mais visíveis nos últimos anos. São também encontradas situações que indicam o surgimento de novas identidades, panindígenas, pluriétnicas ou ainda regionais.

De acordo com Federico Navarrete, os fenômenos desta ordem referem-se "à inesgotável capacidade que os grupos sociais tiveram, e têm, para redefinir suas identidades e suas diferenças em meio à complexa interação com outros

\footnotetext{
13 De maneira muito oportuna, João Pacheco de Oliveira (2004: 70) lembra a especificidade da situação brasileira, uma vez que aqui, contrariamente ao que acontece em outros países tais como a Bolívia, o Peru ou o México, temos que considerar a complexa relação que se estabelece entre o pequeno volume demográfico representado pela população indígena e o seu controle de extensos territórios.

14 Designações alternativas para estes casos são "ressurgimentos" ou "viagens da volta". O trema vem sendo estudado por um importante conjunto de pesquisadores. Aos nomes de Jonathan Hill (1996), Schwartz e Salomon (1999), e Guillaume Boccara (2001), somam-se, no Brasil, os trabalhos de John Manuel Monteiro (2001) e Carlos Fausto (2001).
} 
grupos e com os Estados-nações" (2008: 94). Segundo ainda este mesmo autor, se os ameríndios (assim como os afro-americanos e os imigrantes) costumavam ser pensados

(...) como objetos passivos dos processos de construção nacional e expansão capitalista, o conceito de etnogênese permite descobrir e compreender as complexas estratégias que desenvolveram para reagir, resistir e negociar come esses processos - e também para, na medida do possível, participar e se beneficiar deles (NAVARRETE, 2008: 95).

Desta forma, em países como o México, o Peru ou o Equador, por exemplo, comunidades tradicionalmente identificadas como "camponesas", passam a se apresentar como "indígenas", atualizando elementos de suas culturas antigas, ${ }^{15}$ bem como incorporando subsídios modernos, inclusive na construção de alianças políticas para negociar com os Estados e com outros grupos sociais. Não raras vezes, a atuação de etnólogos, lingüista ou historiadores junto a estes grupos é um elemento essencial deste processo.

Em nosso país, esse fenômeno surge de modo mais evidente nas últimas décadas, quando as histórias regionais passam a ser revisitadas, colocando em cena formas diversas de presença indígena, e evidenciando situações que eram desconsideradas. Contudo, ele também está ligado a uma realidade em que os direitos indígenas tornaram-se mais reconhecidos e respeitados, e as organizações de apoio aos índios se consolidam de forma mais efetiva, passando a ser agentes importantes da causa indígena.

(...) muitos grupos, em áreas de colonização antiga, após terem ocultado sua condição discriminada de indígenas durante décadas, reivindicam novamente sua identidade étnica. No século XIX, sobretudo no Nordeste, com o falso pretexto da inexistência ou de uma assimilação geral dos índios, as terras dos aldeamentos foram liquidadas e (...) duramente disputadas entre os poderes locais. Ressurgem agora etnias (...) que reclamam terras - em geral diminutas, mas que, por se encontrarem em áreas densamente povoadas, enfrentam oposição violenta (CUNHA, 2004: 132).

É preciso destacar que estes grupos emergentes não necessariamente representem a continuidade ou a continuação de elementos ancestrais, podendo ser "fenômenos novos, que podem retomar elementos das diferenças previamente existentes, mas que lhes dão sentidos e funções diferentes e novas" (NAVARRETE, 2008: 91). É dado fartamente conhecido que o movimento em

15 Segundo Federico Navarrete (2008: 96), estes processos dizem respeito ao mundo indígena, assim como à situação de afro-americanos e imigrantes modernos. Entende o autor que estes últimos "revitalizaram e refuncionalizaram aspectos da cultura de seus lugares de origem e também assimilaram traços-chave das culturas locais e nacionais com as quais interagiram, reinventando suas identidades para enfrentar complexas dialéticas de incorporação e exclusão". 
favor dos direitos históricos dos índios está avançando significativamente no país. As organizações indígenas e indigenistas ${ }^{16}$ que se destacam neste processo refletem uma profunda ruptura com práticas tradicionais que se definiam em uma relação de dependência do Estado, contribuindo para reformular as pautas para se pensar o futuro da questão indígena no país (CUNHA, 1995).

Sem dúvidas, o surgimento de um novo interesse pela história dos índios contribui, também, para ampliar a sua visibilidade, sendo a constituição destes novos grupos étnicos, sua categorização e dinâmica, um tema que desperta grande interesse por parte dos especialistas. Estudos desta natureza insistem na necessidade de articular os processos internos de transformação das sociedades indígenas, a outros que lhes são exteriores, provenientes de "situações de contato".

A moderna historiografia que se constrói no Brasil, e nas Américas em geral, abre espaço para pensar nos papéis desempenhados pelas sociedades indígenas que não o de fadados a desaparecer; ou por serem ingênuos e pusilânimes, ou por serem, ao contrário, resistentes. Na condição de aliados ou inimigos dos ocidentais, eles desempenharam importantes e variados papéis no processo histórico aberto com a colonização (MONTEIRO, 2001 e ALMEIDA, 2007).

\section{A nova história indígena}

Segundo John Manuel Monteiro (2004), a "nova história indígena" surge no Brasil, a partir de uma conjuntura particular, em que estudos acadêmicos, especialmente de antropólogos, têm subsidiado demandas e lutas indígenas. Assim como na historiografia de outros países, no Brasil passamos a insistir na necessidade de considerar a "agency", isto é, a capacidade de "ação consciente" dos indígenas (ou de outros "grupos subalternos", termo pelo qual às vezes eles passam a ser a ser denominados, como também os negros e as mulheres, por exemplo). Resultam daí trabalhos que obedecem a orientação de considerar e valorizar as atuações dos próprios índios nos processos históricos nos quais

16 O conceito de indigenismo é portador de uma série de conceitos ideológicos, de cuja avaliação não pretendemos nos ocupar aqui. Não podemos, contudo, deixar de anotar que existem diversos tipos de indigenismos, "freqüentemente antagônicos entre si: de Estado, de Igrejas, de instituições não governamentais. O termo é utilizado por especialistas quando se procura dar unidade aos discursos sobre os índios. O conceito e a prática baseiam-se numa determinada visão dos povos indígenas, não formuladas por eles" (BORGES-BITTENCOURT, 2007: 27). 
eles se inserem.

Como disse Regina Celestino de Almeida ${ }^{17}$,

de vítimas passivas ou selvagens rebeldes que, uma vez vencidos, não movimentavam a história, diferentes grupos étnicos da América passam (...) a figurar como agentes sociais que, diante da violência, não se limitaram ao imobilismo ou à rebeldia. Impulsionados por interesses próprios e visando à sobrevivência diante das mais variadas situações caóticas e desestruturadoras, movimentaram-se em diferentes direções, buscando múltiplas estratégias que incluíam rearticulações culturais e identitárias continuamente transformadas na interação com outros grupos étnicos e sociais (ALMEIDA, 2007: 12).

A nova postura implica, entre outras coisas, em tomar em conta "o ponto de vista dos nativos" na operação de reconstituir os processos históricos que lhes dizem respeito, em atentar para a emergência de novos grupos e identidades e, por fim, em abandonar as compreensões de que os processos históricos coloniais eram marcados pela dicotomia entre a aculturação, a diluição das identidades índias, de um lado, e a luta pela manutenção de tradições imemoriais de outro. Para tanto, ela se nutre de uma série de novas perspectivas teóricas, metodológicas e interdisciplinares que apontam para uma maneira distinta de pensar e escrever a história.

Embora de uma forma um tanto esquemática e arbitrária, podemos distinguir -conforme já assinalamos anteriormente- que, enquanto a historiografia dita "tradicional" havia desconsiderado a presença indígena na história das Américas (esta presença se fazia apenas até o momento da "conquista"), o movimento intelectual dos anos 80, procurando adotar uma postura mais crítica, pretendeu incorporar os "povos sem história" nas narrativas sobre o devir das sociedades americanas. Se bem que esta produção, como parte do movimento da "Nova História", contribuiu para mostrar como a história também se constrói desde os "subalternos", ela acabou por centrar sua atenção de maneira quase única nos processos de "dominação e resistência".

Finalmente, nos anos 90, surgiram (ou ganharam consistência) interpretações que se propunham a repensar alguns destes pressupostos, oferecendo uma reinterpretação do passado das populações indígenas, em que começou a ganhar destaque o tema da negociação. Como afirmou Carneiro da

17 O trabalho "Metamorfoses Indígenas" de 2003, desta autora, constitui-se em importante exemplo dos resultados a que chegam pesquisas assim orientadas, resultados estes que efetivamente "reescrevem" a história vivida pelas sociedades indígenas no Brasil a partir do contato com o Ocidente. 
Cunha (1992: 19), "as sociedades indígenas pensaram o que lhes acontecia em seus próprios termos, reconstruíram uma história do mundo em que elas pesavam e em que suas escolhas tinham conseqüências". É claro que esta é uma cronologia que pode merecer algum reparo, e que os avanços da década de 90 relacionam-se com a produção historiográfica da década anterior.

Efetivamente, no âmbito da produção em língua espanhola, ${ }^{18}$, na década de 80 já apareciam alguns trabalhos que buscavam não optar por esquemas totalizadores e introduzir análises mais matizadas, apontando para o tema da "negociação" que se ampliaria fortemente na década seguinte. Junto a isto, passaram a importar as "estratégias" pelas quais os grupos indígenas influenciaram no desenvolvimento da conquista e da própria sociedade que nascia daí.

Desta forma, a pergunta provocativa sobre "onde estão os índios na história do Brasil?”, com a qual Maria Regina Celestino de Almeida inicia a apresentação de um relativamente recente Dossiê da revista Tempo (2007), pode ser respondida apontando para algumas importantes mudanças no panorama atual. Especialmente nas universidades e centros de investigação, o tema ganha espaço e se atualiza teórica e metodologicamente. Organizações não-governamentais, matérias em jornais e boletins especializados, grupos de estudo e, de forma muito marcante, a consolidação da pesquisa nos diversos cursos de pós-graduação do país, entre outros, têm ajudado a divulgar para um público mais amplo estas reflexões. Podemos lamentar, contudo, que, por outro lado, tais avanços repercutem de maneira muito incipiente na história que se ensina na sala-de-aula.

\section{A escola e o ensino desta história}

Uma rápida avaliação sobre as abordagens que este tema merece nos livros escolares revela o quanto a história que ensinamos é marcada por visões eurocêntricas. De forma geral, as sociedades indígenas fazem sua "entrada" nestes materiais acompanhando o tema da "expansão marítima, comercial e colonial européia". Isto é, elas são inseridas em uma narrativa que organiza princípios de uma "história geral", universal, dentro da qual a especificidade

18 Ver, por exemplo, Steve Stern (1982). 
americana (ou asiática, ou africana) deve se adaptar. A "modernidade" européia passa a ser o paradigma de avaliação e comparação para com as demais sociedades. Em contraposição ao aceleramento dos processos da "Revolução Comercial", encontramos os americanos, "povos da floresta" ou, em outro espectro, as urbanas e sofisticadas sociedades do México ou dos Andes, mas igualmente prisioneiras de um poderoso aparato mítico em que o tempo se repete ciclicamente. Esta constatação reveste-se de uma gravidade ainda maior, se lembrarmos do papel fundamental (e muitas vezes exclusivo) que os livros didáticos desempenham no conjunto dos materiais a disposição de alunos e professores, bem como da sua constituição como "discurso autorizado" entre este público.

Embora tenha havido um acréscimo importante na quantidade e qualidade do que se produz de conhecimento sobre as sociedades indígenas no país, isto ainda pouco repercute naquilo que se ensina nas escolas brasileiras. Temas ligados a esta questão são freqüentemente desconsiderados ou tratados de forma pouco adequada, veiculando a imagem "de um índio genérico, estereotipado, que vive nu na mata, mora em ocas e tabas, cultua Tupã e Jaci e que fala tupi permanece predominante, tanto na escola como nos meios de comunicação" (GRUPIONE, 2004: 483).

Pode-se ainda perceber que, enquanto os espaços reservados para a análise sobre a presença dos negros na história do país se ampliaram, aos indígenas permanecem reservadas apenas as páginas iniciais dos conteúdos de "história do Brasil", que se encerram com a contribuição da cultura indígena e sua "herança". Entre tantos outros efeitos perniciosos desta postura, talvez o mais grave resida em que, apresentando os índios como elementos de uma "préhistória”, presentes apenas nas páginas iniciais dos textos escolares, sugere-se que eles desaparecem da história (assim como dos livros didáticos). Silencia-se desta forma, sobre o passado, mas, sobretudo, sobre o presente das populações indígenas.

Os conteúdos que apresentamos aos nossos estudantes, reificam assim uma visão modelar da trajetória das sociedades ocidentais que toma as mediterrâneas como parâmetro, e que é transposta para aquelas que, desde o XVI, vão sendo objeto da expansão e conquista européia. Podemos ainda afirmar que, grande parte deste esforço explicativo da "história da humanidade" 
dirige-se para a compreensão da formação do Estado Nacional, cuja fórmula seria "uma nação, um povo, um Estado".

Devemos ainda considerar sobre isto, que é na escola -e primordialmente na infância e na adolescência- que recebemos as informações que ajudarão a compor nossas formas de conhecer e lidar com as diferenças culturais, e assim construir a imagem que fazemos do "outro". Nas áreas de colonização alemã e italiana da Região Sul do Brasil, por exemplo, é possível perceber o quanto as memórias históricas são pautadas naquela dos imigrantes europeus. A presença indígena apenas se faz notar quando o "barbarismo" dos nativos é apresentando para contrapor-se (e exaltar) o valor do pioneirismo civilizador dos imigrantes.

Ou seja, encontramos aí um conjunto de estruturas cognitivas profundamente inculcadas na maneira de pensar a história americana e brasileira. Tais estruturas

\begin{abstract}
(...) orientam a percepção, e permitem a reprodução, de um certo universo imaginário em que os indígenas permanecem como povos ausentes, imutáveis, dotados de essências a-históricas e objeto de preconceito: nunca saem dos primeiros capítulos dos livros didáticos; são, vaga e genericamente, referidos como um dos componentes do povo e da nacionalidade brasileiros, algumas vezes tidos como vítimas de uma terrível "injustiça histórica", os verdadeiros senhores da terra. Não surgem enquanto atores históricos concretos, dotados de trajeto próprio, participantes de guerras pelo controle de espaços geográficos específicos, inimigos, mas também muitas vezes aliados, beneficiários e instrumentos dos conquistadores, presentes até hoje em tudo o que se passa em muitas regiões do Brasil. Incapazes de se reelaborarem, eternos portadores de alguns mesmos "traços" que dariam a especificidade do Brasil, nele se diluiriam logo após a chegada do colonizador (SOUZA, 1995: 408).
\end{abstract}

Os próprios indígenas têm tomado consciência desta situação e reivindicado uma nova forma de relacionamento com o Estado e com as diversas instâncias da sociedade envolvente. Neste sentido, encontros de professores indígenas têm acontecido em vários Estados da Federação, nos quais o tema é refletido e debatido, gerando demandas no sentido de que "se respeitem os índios e suas culturas nas escolas não indígenas e nos livros didáticos" (GRUPIONE, 2004: 483).

Para isto é necessário que se perceba o quanto a sociedade branca aprende, na escola, a caricaturizar os índios como frágeis e primitivos, presos às suas culturas ancestrais, às formas tradicionais de se relacionarem com o mundo, de maneira a permanecerem vivendo na "Idade da Pedra". Na Universidade, como educadores, podemos colaborar para a não reprodução 
destes e de outros preconceitos largamente difundidos, através da qualificação da formação de professores para os níveis fundamental e médio. Contribuímos, neste sentido, ao ajudar a desconstruir a visão estereotipada sobre os indígenas que prevalece entre os não índios. E podemos assim, ajudar a firmar a idéia da diferença, que nos faz, nem melhores, nem piores, mas únicos e particulares, e aptos a compreender que histórias particulares fazem parte da história coletiva.

Para concluir, retomo aqui uma argumentação que iniciei em outro momento, e que versa acerca do inoportuno uso de termos genéricos para referirmo-nos às sociedades indígenas com as quais lidamos. Lembro sobre isto que a força simbólica contida nas expressões que utilizamos para categorizar grupos humanos recomenda que, sempre que possível, recorramos aos etnônimos pelos quais estes grupos se reconhecem. Isto significa reconhecer que há um poder muito efetivo -ainda que nem sempre fácil de explicar- no uso da linguagem com a qual escrevemos a história.

\section{Bibliografia}

ALMEIDA, Maria Regina Celestino de. Metamorfoses Indígenas. Rio de Janeiro: Arquivo Nacional, 2001.

Apresentação. Os índios na História: abordagens disciplinares. Tempo. Niterói, v. 12, n. 23, 2007 . Disponível em $<$ http://www.scielo.br/scielo >. Acesso em dezembro de 2007.

BOCCARA, Guillaume. Mundo Nuevos en las Fronteras del Nuevo Mundo. Relectura de los processos coloniales de etnogenesis, etnificacion y mestizaje en tiempos de globalización. Nuevo Mundo, Mundos Nuevos. n. 1, 2001, Disponível em <http//nuevomundo.revues $>$. Acesso em 20 de março de 2004.

BORGES BITTENCOURT, Liberdad. A formação de um campo político na América Latina. As organizações indígenas no Brasil. Goiás: Ed. da UFG, 2007.

CUNHA, Manuela Carneiro da. História dos Índios do Brasil. São Paulo: Cia das Letras; Secretaria Municipal de Cultura, FAPESP, 1992.

. IN: SILVA, Aracy Lopez da Silva; GRUPIONI Luiz Donisetti Benzi. (Org.). A questão indígena na sala de aula. Novos subsídios para professores de $1^{\mathrm{o}}$ e $2^{\mathrm{O}}$ graus. 1 ed. Brasília: MEC, 1995, pp. 129-141.

FAUSTO, Carlos. Deuses, Machados e Jaguares. IN: Inimigos Fiéis. História, guerra e xamanismo na Amazônia. São Paulo: EDUSP, 2001.

. Os índios antes do Brasil. Rio de Janeiro: Jorge Zahar Ed., 2000.

GRUPIONI, Luis Donizeti Benzi. Livros didáticos e fontes de informação sobre as sociedades indígenas no Brasil. In: SILVA, Aracy Lopez da Silva; GRUPIONI 
Luiz Donisetti Benzi. (Org.). A questão indígena na sala de aula. Novos subsídios para professores de $1^{\mathrm{O}}$ e $2^{\circ}$ graus. Brasília: MEC, 1995, pP. 481-526.

HALPERIN DONGUI, Túlio. Historiografia Colonial Hispano-Americana e Multiculturalismo: a História da Colonização entre a Perspectiva do Colonizador e do Colonizado. In: Estudos Históricos, 1997. Disponível em $<$ www.cpdoc.fgv.br/revista $>$. Acesso em 25/04/2005.

HILL, Jonathan. (Ed.) History, Power and Identity: Ethnogenesis in the Americas. 1492-1992. Iowa City: University of Iowa Press, 1996, pp. 20-35.

LEÓN-PORTILLA, Miguel. A conquista da América vista pelos índios. Relatos astecas, maias e incas. Tradução de Augusto Ângelo Zanata. Petrópolis: Vozes, 1984 .

A visão dos vencidos. A tragédia da conquista narrada pelos astecas. Tradutores Carlos Urbin e Jaques Waiberg. Porto Alegre: LP\&M, 1985.

MENGET, Patrick. Entre memória e história. IN: NOVAES, Adauto (org). A outra margem do Ocidente. São Paulo: Cia das Letras, 1999, pp. 153-165.

MONTEIRO, John Manuel. Tupis, Tapuias e historiadores: estudos de história indígena e do indigenismo, Tese de Livre-Docência em Antropologia, IFCHUnicamp, Campinas, 2001. Disponível em <www.ifch.unicamp.br/ihb >. Acesso em março 2006.

NAVARRETE, Federico. A invenção da etnicidade nos estados-nações americanos nos séculos XIX e XX. Tradução de Eduardo Natalino dos Santos. In: HARRIS, Marluza M. e HEINZ, Flávio M. A História e seus territórios. Livro de Conferências do XXIV Simpósio Nacional de História. São Leopoldo, Oikus; ANPUH, 2008, pp . 89-114.

RESTALL, Matthew. Sete mitos da conquista européia. Tradução de Cristina de Assis Serra. Rio de Janeiro: Civilização Brasileira, 2006.

ROCHA, Leandro Mendes (org). Etnicidade e nação. Goiânia: Cânone Editorial, 2006.

SCHWARTZ, Stuart e SALOMON, Frank. New peoples and new kind of people: adaptation, readjustment, and ethnogenesis in South American indigenous societies (Colonial Era). IN: SCHWARTZ, Stuart e SALOMON, Frank, (Eds). The Cambridge history of the natives peoples of the Americas: South America. Parte 2. v.3. Cambridge: Cambridge University Presss, 1999, pp. 443-501..

SOUZA LIMA, Antonio Carlos. Um olhar sobre a presença das populações nativas na invenção do Brasil. IN: SILVA, Aracy Lopez da Silva; GRUPIONI Luiz Donisetti Benzi, (Org.). A questão indígena na sala de aula. Novos subsídios para professores de $1^{\circ}$ e $2^{\circ}$ graus. Brasília: MEC, 1995, pp. 407-419.

STERN, Steve. Peru's indians people and the challenge of the indians conquest: Huamaga to 1640. Madison: 1982.

WACHTEL, Nathan. Los vencidos; los indios del Perú frente a la conquista española (1530-1570). Madrid: Alianza Editorial, 1976.

Colaboração recebida em 31/05/2009 e aprovada em 16/06/2009. 